\title{
SHIP2FAIR - Martini \& Rossi: integration of Solar Heat in Industrial Process - Preliminary evaluation
}

\author{
Stefano Barberis ${ }^{1, *}$, Francesco Peccianti ${ }^{1}$, Luca Castellino $^{2}$, Thomas Bolognesi ${ }^{3}$, and \\ Alessandro Bortoletto ${ }^{3}$ \\ *Stefano.barberis@,rina.org \\ ${ }^{1}$ RINA Consulting S.p.A., Via Liri 27, 16145 Genova (GE), Italy \\ ${ }^{2}$ Bacardi-Martini\&Rossi, Piazza Luigi Rossi, 2, 10023 Chieri (TO), Italy \\ ${ }^{3}$ LINKS Foundation, Via Pier Carlo Boggio, 61, 10138 Torino (TO), Italy
}

\begin{abstract}
SHIP2FAIR is a H2020 European funded project ${ }^{\dagger}$, which aim to foster the integration of solar heat in industrial processes from the agrofood sector facilitating the integration of solar heat production in low temperature processes. Based on the assessment of the industrial process for the production of different spirits and the local solar potential in Pessione plant (TO) of Martini \& Rossi - one of the four demosite of the project -, the preliminary results that guided the choice of the most suitable solar collectors (Fresnel) and the definition of the thermo-economic parameters for the solar plant are hereby presented. The preliminary assessment takes into account different perspectives from the industrial and economic point of view: the availability of suitable surfaces, the economics of the investment and the best processes to be fed by solar produced steam towards a preliminary techno-economic feasibility study. The starting points for the analysis have been the characterization of the thermal demand in terms of necessary temperature level $\left({ }^{\circ} \mathrm{C}\right)$, overall consumption and time distribution. The following step has been the identification of the suitable collectors to be installed taking into account the thermal parameters presented before, the boundary conditions of the industrial facility (e.g. space available, orientation, etc.), the technical characteristics of the collector itself and the solar irradiation available considering the plant's location. Moreover, the complex thermal facility in the factory, constituted by multiple (3) gas boilers and a Combined Heat and Power (CHP) plant in two different but linked pressurized steam loops, is taken into account for the definition of the solar collectors configuration and their integration via the proper management of heat generators and storage. The calculations are based on the expected thermal (steam) production guaranteed by the solar collectors and avoided GHG based on the reduction of gas fired boilers consumption.
\end{abstract}

\footnotetext{
* Corresponding author: stefano.barberis@rina.org

$\dagger$ This project has received funding from the European Union's Horizon 2020 research and innovation programme under grant agreement No 792276 - http://ship2fair-h2020.eu/
} 


\section{Introduction}

The main goal of SHIP2FAIR is to foster the integration of solar heat in industrial processes from the agro-food sector by developing and demonstrating at real industrial sites a set of technologies, tools and methods for the development of industrial solar heat projects during its whole life-cycle. Industry accounted for a quarter of the EU's final energy consumption in 2012. European industry has cut its energy intensity twice as fast as the United States since 2000. As reported by [1,2], in 2012, the share of heating in the final energy demand of the European industry was $71 \%$ (60\% for process heating and $11 \%$ for space heating). Significant potential remains particularly in agro-food sector where the temperature in play are suitable to exploit sustainable heating technologies (not only solar thermal) currently robust and widespread for domestic purposes. By exploiting these technologies, it is possible to reduce energy costs in industry by $10-30 \%$ with investments that pay for themselves in less than 5 years [3].

While in 2011 solar heat could mainly be used for processes ranging from $20^{\circ} \mathrm{C}$ to $100^{\circ} \mathrm{C}$ as reported by [4], SHIP2FAIR targets to promote the penetration and the affordability of higher temperature technologies by demonstrating them in industrial demosites. In this perspective the Martini \& Rossi case is particularly significant as direct steam production at more than $170^{\circ} \mathrm{C}$ is foreseen.

\section{Plant description and scope of the work}

Martini \& Rossi (M\&R) is the Italian company of the Bacardi Group and it is located in Pessione of Chieri (TO) since 1863. Pessione plant is the historical site where all the products in all the receipts are produced. The location of the plant as it has been one of the first step to identify the resource potential which is critical in the pre-design, design and operation of every solar thermal plant and it is illustrated in Fig. 1 in its relevant components (global and direct irradiance).

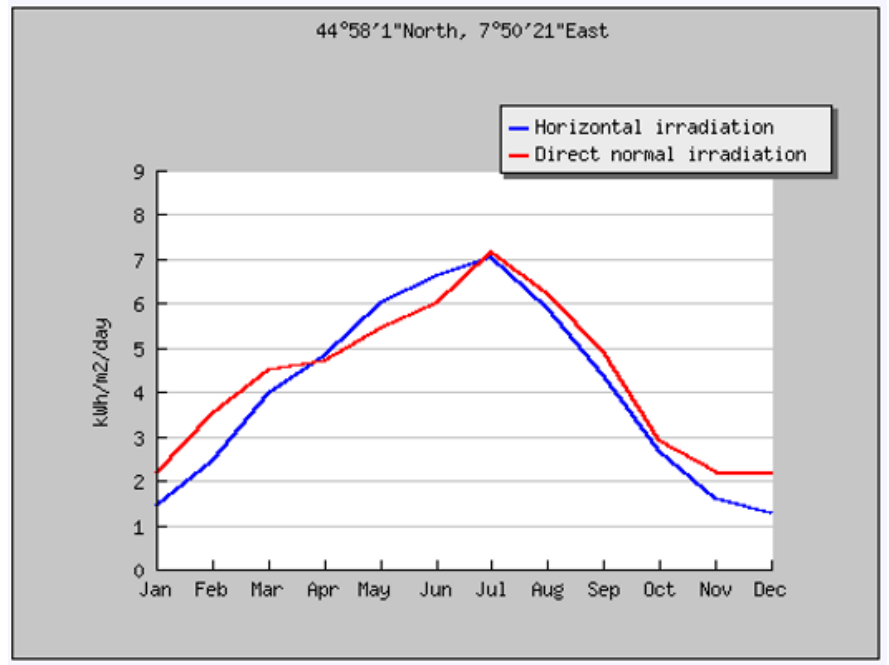

Fig. 1. Solar irradiance in Pessione (source: PVGIS)

The second relevant input necessary to perform the preliminary evaluation of the integration of Solar Heat in Martini \& Rossi industrial process has been the thermal characterization of the steam network with respect to temperature level, overall heat 
consumption and how this consumption is distributed along the year and the days. The first relevant information is that in Pessione plant there are two saturated steam loops at two different pressure level: the first one at around 3 bar $\left(130^{\circ} \mathrm{C}\right)$ and the second one at 9 bar $\left(175^{\circ} \mathrm{C}\right)$ - values are not constant due to the dynamic nature of the system -, interconnected in the boiler room via a heat collector. These two loops are currently equipped with 3 gas boilers (connected to the high pressure collector) of $3900 \mathrm{~kW}$ each and a CHP unit with a thermal power of $860 \mathrm{kWt}$. The result of the preliminary thermal characterization of the plant is presented in Fig. 2 where the hourly demand [\% on total demand] is presented on a 2-hour basis for a typical day summer and winter.

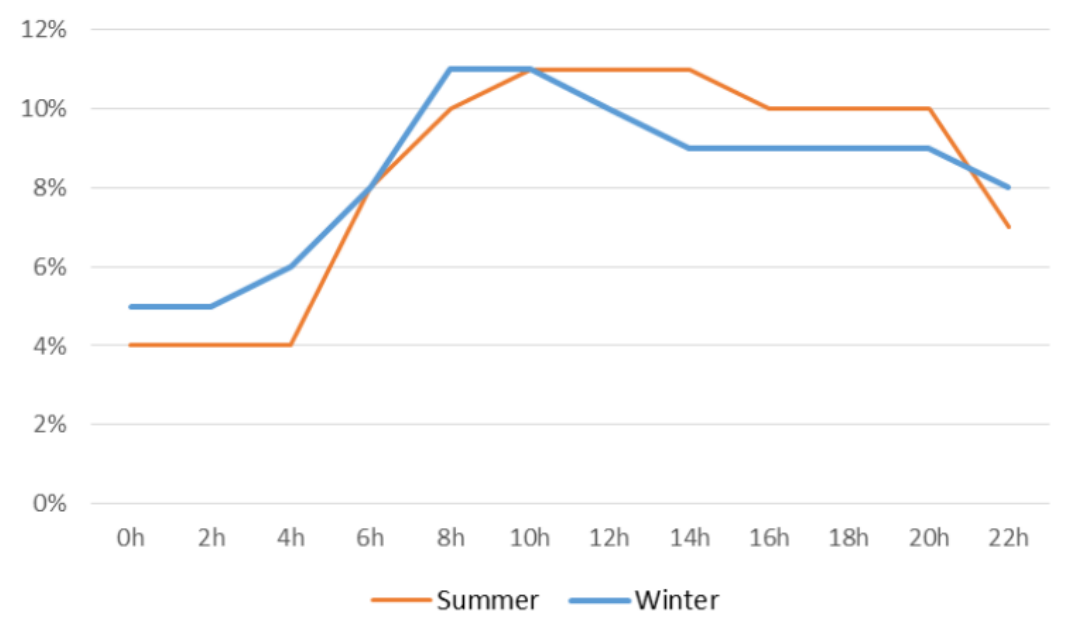

Fig. 2. Thermal demand distribution over the day of a typical day (x-axis hours of the day - y-axis $\%$ on total thermal demand)

\section{Choice of the collector and thermo-economic calculation}

Two additional constraints have been taken into account, linked to the temperature level required for the optimal operation of the plant and to the available space for the installation. As the exact consumption linked to the two pressure loop is not measured, in order to guarantee the maximum possible solar fraction defined as the energy provided from the solar source divided by the total energy needed as defined in Eq. 1:

$$
f=\text { Esol } / \text { Etot }
$$

the choice of a solar technology able to deliver steam up to pressure level as required by the loops and currently generated by boilers and CHP has been therefore identified also considering that the basic control strategy implemented in M\&R consists in an automated valve able to transfer fluid from the high pressure loop if the low pressure one drops below a pre-defined quota. Based on this, as also presented by [5], where different solar thermal technologies are presented with respect to their applicability in terms of temperatures, the linear Fresnel technology has been identified as suitable to satisfy the need particularly for what it concerns steam production reliability considering temperature achievable by the collectors as well as lighter substructure if compared with parabolic trough 
The preliminary expected solar production has been therefore calculated taking into account the average local irradiation value (DNIavg), an average solar collector thermal efficiency ( $\eta$ ), an operating factor (OF) and the installed surface (S) as per Eq. 2. The first parameter has been derived from PVGIS tool [5], while the second one was derived both from literature [6] information and input from technology manufacturer. Finally the third one has been considered in order to obtain a peak power of about 1MWt from the solar plant. All the considered values are resumed in Table 1.

Table 1. Main values used in the calculations

\begin{tabular}{|l|r|}
\hline DNIavg $\left[\mathrm{kWh} / \mathrm{m}^{2}\right.$ year $]$ & 1580 \\
\hline$\eta$ & 0,65 \\
\hline Surface $\left[\mathrm{m}^{2}\right]$ & 2500 \\
\hline Operating Factor & 0,7 \\
\hline Turnkey surface cost $\left[€ / \mathrm{m}^{2}\right]$ & 270 \\
\hline Natural gas cost $\left[€ / \mathrm{m}^{3}\right]$ & 0,3 \\
\hline
\end{tabular}

$$
E_{\text {sol }}=D N I_{\text {avg }} * \eta * S * O F \simeq 1.8 \mathrm{GWh} / \text { year }
$$

The expected solar production can be straightforwardly translated in natural gas savings as natural gas is the heating source in Martini \& Rossi plant in Pessione, via boilers and the CHP. Considering the gas price paid by Martini \& Rossi in 2017 and the objective cost for a turnkey plant as presented in SHIP2FAIR project, the calculated payback-period is 8,82 years which is relevant considering that due to available roof surfaces and project funding unfortunately only $1 \mathrm{MW}$ of the global thermal demand can be covered by solar production.

This PBP is also aligned to SHIP2FAIR objectives which aim to promote economically viable SHIP technologies and projects with $\mathrm{PBP}<10$ yrs.

In parallel, the greenhouse gasses emission avoided are directly linked to the natural gas saved by providing heat via the solar collectors instead of from the combustion of a fossil fuel. For natural gas, the reference value is $234 \mathrm{~g} / \mathrm{kWh}$ as presented in [7], which corresponds to 420 ton/year of $\mathrm{CO}_{2}$.

\section{Conclusions}

This preliminary evaluation performed taking into account the needs and the peculiarities of Martini \& Rossi plant shows that significant solar installation with PBP of about 10 years can be achieved even without external incentives. As a matter of fact, in many EU and nonEU countries there are national subsidies on renewable sources installation and avoided GHG that could incentivise this kind of plants. Moreover, the foreseen solar fraction, which is not greater than $20 \%$ on average has two major consequences: firstly, the control logic is quite simple as the solar heat produced can be in principle directly injected in the high pressure steam loop and, secondly, the storage size can be reduced as its main role would be to smooth the solar production and not managing the thermal load. It is also worthy to underline that the production of flat solar thermal collectors at a lower temperature and pressure could be potentially integrated in the low pressure operating loop

Finally, in this preliminary evaluation some physical constrains has not been fully considered as the specification of the plant has not been yet fully defined. This kind of constraints to the current stage of SHIP2FAIR project are under investigation and they represent, in general, a crucial part of every project as in the industrial environment space has a key value and it could bear extra costs and/or technical bottlenecks that a preliminary analysis cannot identify. 


\section{References}

[1] TrustEE, H2020, GA 696140, D1.1: Report on current status of Process Heat in Europe: sectors, processes, geographical distribution, system layouts and energy sources, Public Report

[2] European Commission under contract $\mathrm{N}^{\circ} \mathrm{ENER} / \mathrm{C} 2 / 2014-641$, Mapping and analyses of the current and future (2020 - 2030) heating/cooling fuel deployment (fossil/renewables), Final Report September 2016

(https://ec.europa.eu/energy/sites/ener/files/documents/mapping-hcexcecutivesummary.pdf, last access: 02/05/2019)

[3] ABB, Energy efficiency - the fast track to a sustainable energy future, Public Report, (2015)

[4] Intergovernmental Panel on Climate Change, Renewable Energy Sources And Climate Change Mitigation - Summary For Policymakers And Technical Summary, Public Report, (2011)

[5] PVGIS (http://re.jrc.ec.europa.eu/pvgis/apps4/pvest.php\#, last access: 02/05/2019)

[6] P. L. Singh, R.M. Sarviya, J.L. Bhagoria, Thermal performance of linear Fresnel reflecting solar concentrator with trapezoidal cavity absorbers, Applied Energy, 87 (2010), 541-550

[7] SHIP2FAIR, H2020, GA 792276, D2.3: Key Performance Indicators to evaluate the integration of solar heating in industrial processes, Public Report 